\title{
Study of grown single crystal diamond by optical and X-ray spectroscopy
}

\author{
D.B. Radishev ${ }^{1}$, A.L. Vikharev ${ }^{1}$, A.M. Gorbachev ${ }^{1}$, A.B. Muchnikov ${ }^{1}$, \\ P.A. Yunin' ${ }^{2}$, V.N. Amosov', N.B. Rodionov ${ }^{3}$ \\ ${ }^{1}$ Institute of Applied Physics of the Russian Academy of Sciences, Nizhny Novgorod, Russia \\ ${ }^{2}$ Institute for Physics of Microstructures of the Russian Academy of Sciences, Nizhny Novgorod, Russia \\ ${ }^{3}$ Russian State Research Center, Troitsk Institute for Innovation and Fusion Research, Troitsk, Moscow, Russia
}

\section{Introduction}

Single crystal diamond is a promising material for the creation of modern semiconductor electronic highfrequency and high-power devices due to its unique physical properties. Successful realization of all advantages of diamond requires high-quality ("electronic-grade") material that is the material with a lowest content of impurities and defects. Both natural diamond and a synthetic high-pressure high-temperature (HPHT) diamond do not exhibit quality necessary for modern semiconductor devices. At present the only method for obtaining artificial single crystal diamond of high quality that is reproducible from crystal to crystal is the chemical vapour deposition in plasma chemical reactors utilizing microwave discharge plasma in carbon-containing gas mixture (MPACVD method). In the process of CVD growth of diamond, the impurities concentration in the resulting material depends on the reactant gas mixture purity, also some of the defects in the HPHT substrate may be "overgrown" during deposition, resulting in the diamond with quality significantly better than seed substrate quality. In this work we investigate single crystals of CVD diamond with a low concentration of substitutional nitrogen, grown by microwave plasma-assisted chemical vapour deposition.

\section{Experiment}

CVD diamond single crystal layers were grown in a $2.45 \mathrm{GHz}, 5 \mathrm{~kW}$ microwave plasma-assisted CVD reactor. Block diagram of the experimental setup is shown in Fig. 1. Reactor is based on the cylindrical cavity (1) with a diameter that allows exciting of three axially symmetric modes $\mathrm{TM}_{01 \mathrm{n}}, \mathrm{TM}_{02 \mathrm{n}}$ and $\mathrm{TM}_{03 \mathrm{n}}$. Upper (2) and lower (3) walls of the cavity act as mode converters. On the lower wall of the cavity, outside the quartz dome (4) limiting the gas volume, and near the side wall of the cavity, is a ledge (5) of variable height with an internal diameter selected so that the $\mathrm{TM}_{03 \mathrm{n}}$ mode decays in the bottom part of the cavity. As a result of superposition of three modes: $\mathrm{TM}_{01 \mathrm{n}}, \mathrm{TM}_{02 \mathrm{n}}$ and decaying $\mathrm{TM}_{03 \mathrm{n}}$, the distribution of the near electric field is formed so that the deposition of diamond is highly uniform: in case of polycrystalline diamond films it corresponds to 5\% thickness difference at a diameter of $75 \mathrm{~mm}$. Microwave power is fed into the

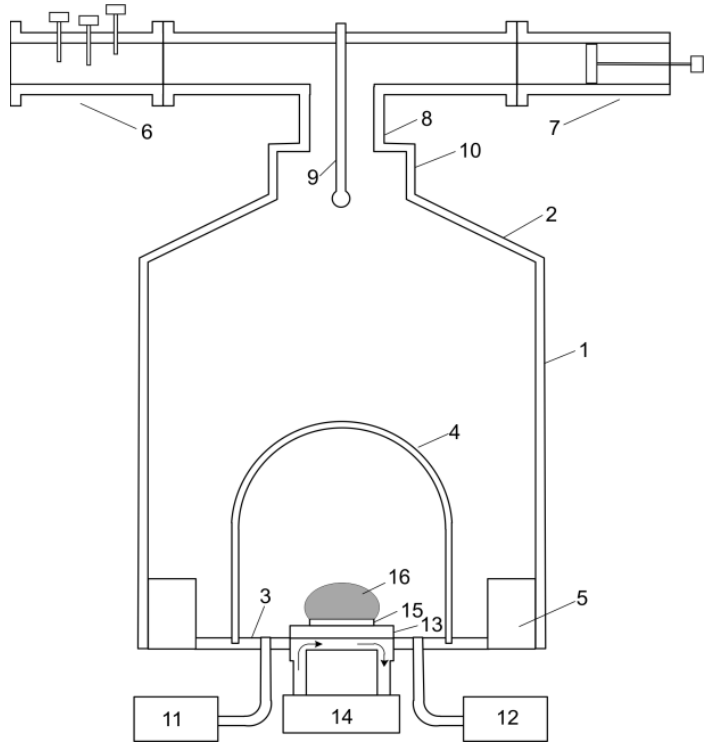

Fig. 1. Experimental setup: 1 - cylindrical cavity, 2 - circular cone, 3 - bottom cavity wall, 4 - quartz dome, 5 - step ledge, 6 - waveguide system, 7 - plunger, 8 - coaxial line, 9 - antenna, 10 - shorted cylindrical waveguide, 11 - gas supply system, 12 - gas evacuation system, 13 - substrate holder, 14 - substrate cooling system, 15 - substrate, 16 - microwave discharge

cavity via tunable waveguide system (6) with plunger (7), connected to coaxial line (8) with antenna (9) that excites cylindrical cavity via shorted cylindrical waveguide (10) and circular cone (2). Reactor is equipped with automatic systems for supply (11) and pumping (12) of reactant gases. Substrate holder (13) is connected with water cooling system (14).

The epitaxial layers were grown on type IIa highpressure high-temperature (HPHT) (100)-oriented single crystal seed diamonds of approximate dimensions $3 \times 3 \times 0.5 \mathrm{~mm}$, produced by New Diamond Technology company (Sistroretsk, Russia) and the Technological Institute for Superhard and Novel Carbon Materials (Troitsk, Moscow, Russia). Six samples were used for deposition at different conditions: with varied content of methane in hydrogen-methane mixture, incident microwave power from 2.5 to $2.9 \mathrm{~kW}$, at pressure 130 to 200 Torr and at substrate temperature of $950^{\circ} \mathrm{C}$. Also CVD-04 and S-01 samples were grown with gas purify-

\begin{tabular}{|c|c|c|c|c|c|c|c|c|c|}
\hline \multirow[t]{2}{*}{ № } & \multirow[t]{2}{*}{ Sample } & \multirow{2}{*}{$\begin{array}{c}\text { Layer } \\
\text { thickness, mm }\end{array}$} & \multirow{2}{*}{$\begin{array}{c}\mathrm{G}, \\
\mu \mathrm{m} / \mathrm{h}\end{array}$} & \multirow{2}{*}{$\begin{array}{c}\text { Raman } \\
\text { FWHM, } \mathrm{cm}^{-1}\end{array}$} & \multirow{2}{*}{$\begin{array}{l}\text { Miscut } \\
\text { angle, }^{\circ}\end{array}$} & \multicolumn{3}{|c|}{ Deposition regime } & \multirow[t]{2}{*}{ Purifiers } \\
\hline & & & & & & $\mathrm{CH}_{4}, \%$ & Power, kW & P, Torr & \\
\hline 1 & CVD-01 & 0.8 & 13.8 & 1.61 & & $6 \%$ & 2.7 & 200 & - \\
\hline 2 & CVD-02 & 0.85 & 14.5 & 1.53 & 1.83 & $6 \%$ & 2.9 & 200 & - \\
\hline 3 & CVD-03 & 0.3 & & 1.59 & 2 & $6 \%$ & 2.8 & 200 & - \\
\hline 4 & CVD-04 & 0.25 & 10 & 1.65 & 0.53 & $6 \%$ & 2.8 & 195 & $\mathrm{H}_{2}$ \\
\hline 5 & CVD-05 & 0.1 & 6.5 & 1.74 & 0.03 & $4 \%$ & 2.8 & 150 & - \\
\hline 6 & S-01 & 0.25 & 3.8 & 1.56 & 0.28 & $3 \%$ & 2.5 & 130 & $\mathrm{H}_{2}, \mathrm{CH}_{4}$ \\
\hline
\end{tabular}


ers, for hydrogen only (CVD-04) and both for hydrogen and methane (S-01). Summary of deposition regimes are presented in the Table. Samples CVD-01, CVD-02 и CVD-03 were separated (laser-cut) from the substrate, samples CVD-04 and S-01 were investigated while still on the substrate.

a)

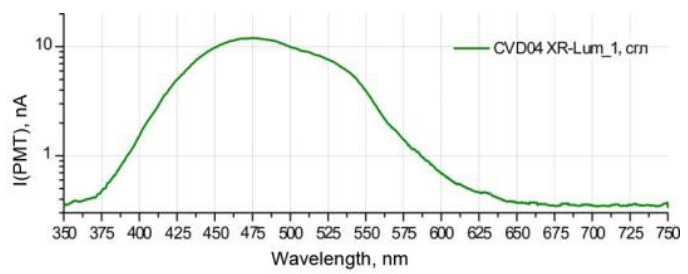

b)

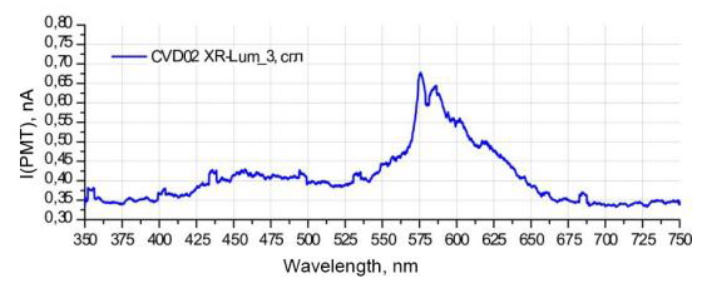

Fig. 2. XRS spectrum of: $a-$ CVD-04, $b$ - CVD-02

Investigations of CVD diamond layers, both separated and not separated from the substrate, were carried out using micro-Raman and photoluminescence (PL) spectroscopy methods at liquid nitrogen temperature, as well as method of X-ray luminescence spectroscopy (XRS). The most common impurity introduced into the diamond during deposition is nitrogen. It arises both from atmosphere leaks into the reactor, and from nitrogen contamination of source reactant gases. To eliminate leaks reactor was thoroughly leak-tested $\left(\mathrm{N}_{2}\right.$ leaks may also be detected by $\mathrm{CN}$ line emission in the optical spectrum of the discharge). To get rid of the nitrogen traces in source gases, gas purifiers were used for deposition of some of the substrates. Nitrogen incorporation into the diamond occurs mostly in form of substitutional nitrogen atoms $\left(\mathrm{N}_{\mathrm{s}}\right)$. If there is a vacancy near the $\mathrm{N}_{\mathrm{s}}$ atom, nitrogenvacancy complex (N-V) may be formed. Nitrogenvacancy complex is more energetically favorable than separated nitrogen and vacancy, also at temperatures higher than $650{ }^{\circ} \mathrm{C}$ (that is typical for CVD diamond growth condition) vacancies diffusion occurs in diamond, which leads to effective conversion of $\mathrm{N}_{\mathrm{s}}$ atoms to $(\mathrm{N}-\mathrm{V})$ centers [1]. Conversion ratio of $\mathrm{N}_{\mathrm{s}}$ to $(\mathrm{N}-\mathrm{V})$ almost does not depend on $\mathrm{N}_{\mathrm{s}}$ and is about 1:300 (within the range $1: 100$ to $1: 1000,[2])$. It is hard to directly measure small concentration of $\mathrm{N}_{\mathrm{s}}$ in diamond, but photoluminescence at liquid nitrogen temperature is known to be very sensitive method for detection of $(\mathrm{N}-\mathrm{V})$ centers and therefore can be used for $\mathrm{N}_{\mathrm{s}}$ concentration estimation.

Raman/PL spectra of the samples grown without purifiers have pronounced luminescence lines of $(\mathrm{N}-\mathrm{V})^{0}$ and $(\mathrm{N}-\mathrm{V})^{-}$, along with luminescence of $(\mathrm{N}-\mathrm{V})$ centers. Width (full width at half maximum, FWHM) of Raman peak of diamond is within $1.53-1.74 \mathrm{~cm}^{-1}$, that corresponds to high crystalline perfection of diamond. Raman and PL spectrum of S-01 sample, grown with both hydrogen and methane purifiers, does not have detectable lines corresponding to $(\mathrm{N}-\mathrm{V}),(\mathrm{N}-\mathrm{V})^{0}$ and $(\mathrm{N}-\mathrm{V})^{-}$lumines-cence. According to sensitivity estimation performed earlier using substrate with thin nitrogen-doped layer with known concentration, this corresponds to $\mathrm{N}_{\mathrm{s}}$ concentration of less than $5 \mathrm{ppb}\left(5 \cdot 10^{-9}\right)$. That means that our CVD synthesis setup allows growing diamond with a low level of impurity nitrogen using source gas purifiers.

Investigation of CVD diamond samples were also made using X-ray luminescence spectroscopy - the study of spectrum of optical emission of diamond occurring under X-ray irradiation. Broad luminescence band at about $480 \mathrm{~nm}$ (A-band) is usually attributed to concentration of different kinds of defects that act as centers of electron-hole recombination [3]. XRS spectra of samples not detached from substrate demonstrate bright A-band luminescence associated with HPHT substrate defects (Fig. 2a). XRS spectra of samples separated from substrate shows much lower luminescence near $480 \mathrm{~nm}$, but have small peak near $575 \mathrm{~nm}$, possibly associated with nitrogen impurities (for sample grown without purifier, Fig. 2b). This shows that the concentration of various defects, which act as the centers of electron-hole recombination, is much lower in grown CVD layers than in HPHT substrates used. Such results demonstrate the decrease of the concentration of defects during the growth of CVD diamond and the possibility of obtaining a CVD diamond with a quality significantly superior to the quality of the HPHT substrate used.

\section{Conclusion}

Single crystal diamond is a promising material for the creation of electronic devices due to its unique physical properties, but it requires material with a low content of impurities and defects. Six experiments for deposition of CVD diamond layers were made, at different growth conditions and with or without source gases purifiers. Obtained CVD diamonds were examined using microRaman and PL spectroscopy, and X-ray spectroscopy. Results show that it is possible to obtain CVD diamond with no nitrogen contamination detectable with PL method and with defects concentration significantly lower than in HPHT type IIa diamond.

\section{Acknowledgments}

This work was supported by a grant from the Russian Science Foundation (Project № 17-19-01580).

\section{References}

1. Optical Engineering of Diamond, Edited by Rich P. Mildren and James R. Rabeau, 2013 Wiley-VCH Verlag \& Co.

2. A. M. Edmonds, U. F. S. D'Haenens-Johansson, R. J. Cruddace, M. E. Newton, K.-M. et al. Production of oriented nitrogen-vacancy color centers in synthetic diamond // Phys. Rev. B, 2012, 86, 035201.

3. Bernhard Dischler, Handbook of Spectral Lines in Diamond, Springer-Verlag Berlin Heidelberg, 2012. 